\title{
APROXIMACIÓN AL DESARROLLO ENDÓGENO DE PAMPLONA
}

Eliseo Villamizar Antolinez*

\footnotetext{
* Economista Universidad Nacional de Colombia, Especialista en Finanzas Públicas ESAP. Profesor Universidad de Pamplona. E-mail: celiseo@hotmail.com
} 


\section{APROXIMACIÓN AL DESARROLLO ENDÓGENO DE PAMPLONA}

\section{RESUMEN}

En el presente documento se hace una presentación reducida de un trabajo más amplio que aun se encuentra en desarrollo, pretende realizar una primera aproximación al proceso de desarrollo endógeno del municipio de pamplona.

Cómo abordar el problema complejo y sistémico del desarrollo endógeno exige un trabajo transdisciplinar; nos hemos señalado como objetivo inicial el partir de la identificación de su componente económico y particularmente del "crecimiento económico" y de sus características más relevantes: a) la historia; b) desarrollo de procesos económicos espontáneos; c) identificación de emprendedores y, d) cambios hacia procesos complejos y crecimiento de la productividad, generación de sinergias e impactos de nuevos procesos de emprendimiento.

Palabras Claves: Crecimiento económico, Desarrollo endógeno, sinergia, Procesos espontáneos.

\section{ABSTRACT}

This document is a small presentation of a broader work is still in development, aims to conduct a preliminary approach to endogenous development process of the municipality of Pamplona.

Addressing the complex and systemic problem of endogenous development requires crossdisciplinary work, we have identified as the initial target identification from its economic component, particularly the "economic growth" and its most important characteristics: a) history, b ) development of spontaneous economic processes, c) identification of entrepreneurs and, d) changes to complex processes and productivity growth, generating synergies and impacts of new processes of entrepreneurship.

Keywords: Economic growth, endogenous development, synergy, spontaneous process.

\section{Face IssN 1794-9920}

Recepción: Julio de 2008 Revisión: Diciembre de 2008 Aceptación: Diciembre de 2008 


\section{INTRODUCCIÓN}

No se pretende en esta primera aproximación plantear las cuestiones integrales mas significantes del proceso como bien las señala Boisier (1999) cuando afirma que el consiste en el "cambio estructural" de un territorio (región o localidad), de progreso de la comunidad y los individuos que la componen; dentro de una "dimensiones" espacial, social e individual que se expresa en la transformación de la sociedad civil, el acentuamiento de sentido de pertenencia regional y donde sus miembros puedan alcanzar su plena realización como persona humana.

Para abordar el problema, debimos identificar algunas teorías del desarrollo local y regional que nos van a servir de guía en el proceso de comprensión inicial, teniendo en cuenta que ellas no son paradigmas estáticos y que cada localidad o región permite, en concordancia con una aprehensión adecuada de la realidad, plantear las condiciones particulares y únicas de los procesos de desarrollo endógeno.

En segundo lugar, poner al desnudo las características más generales del proceso histórico pamplonés, que han permanecido y que le dan la identidad especifica: las características identificadoras de ciudad, dejando al descubierto los elementos que forman parte de ese hilo conductor y que se expresan en eventos que existieron, existen y continuaran existiendo: el turismo, el ser ciudad estudiantil y centro prestador de servicios tanto privados, estatales y religiosos.

En cuarto lugar, identificar los nuevos elementos dinamizadores de la posibilidad de desarrollo endógeno positivo y los impactos que generó en el entorno.

Finalmente, intentar una propuesta de desarrollo, que tenga en cuenta los hilos conductores y que refuerce la identidad económica que ha persistido y que se convierte nuevamente en la posibilidad de desarrollo de pamplona.

Tengo, finalmente, que reconocer a los integrantes del Semillero de Investigación en Desarrollo Endógeno del Departamento de Economía de la Universidad de Pamplona el cual dirijo, su colaboración en el adelanto del documento y que está integrado por los estudiantes de último semestre Luz Adriana Bohórquez, Ingrid Lorena Álvarez, Gina Lorena Loza, Alejandra Álvarez, Nathaly Hernández, y Santiago Parales.

\section{Breve exposición de la teoría del desarrollo endógeno}

En los últimos tiempos se han venido construyendo propuestas teóricas de desarrollo territorial, de desarrollo local y específicamente la teoría del Desarrollo endógeno.

En año 1975 se empieza a percibir la problemática territorial, pues la política desarrollada se basaba en modelos de crecimiento concentrado que tenía como 
propósito beneficiar los territorios con recursos. Empezó a ganar fuerza la idea de que el Desarrollo Económico Local debía propiciarse sobre la base de sus propios recursos, sin negar la posibilidad de que puedan dirigirse desde afuera algunos recursos imprescindibles para el desarrollo en determinadas localidades que estén más deprimidas.

Al respecto de estas discusiones, se fue construyendo a partir de la investigación, propuestas que identificaban de manera clara la necesidad de voltear la mirada hacia lo local:

"Las políticas de desarrollo económico local constituyen una respuesta necesaria a los principales retos e imperativos del ajuste estructural real de las economías latinoamericanas, ya que se orientan de forma fundamental a asegurar la introducción de las innovaciones tecnológicas y organizacionales en la base misma del tejido productivo de los diferentes territorios". 1

Vázquez Barquero precisa aun más estos conceptos cuando reseña que el desarrollo Económico Local se convierte en los años ochenta en la estrategia de desarrollo territorial dominante:

"Ha quedado atrás la época en que la economía era una cuestión que sólo afectaba las decisiones de la administración central del estado y de las grandes empresas y en la que, los administradores locales sólo se preocupaban de gestionar los servicios públicos y de corregir los impactos espaciales y urbanísticos de las actuaciones económicas. Sus objetivos son pragmáticos, los instrumentos y las acciones no sólo tratan de resolver problemas concretos, sino que le dan mayor importancia a la competitividad y a la difusión de las innovaciones y, desde el punto de vista operativo, las iniciativas locales se instrumentan a través de formas flexibles de organización como son las agencias de desarrollo". ${ }^{2}$

Las características de las localidades cambian por lo que las acciones de las estrategias se modifican sustancialmente y puede ir desde el fomento del emprenderismo (entendido en su real dimensión) para generar capacidad empresarial hasta la solución de los problemas estructurales.

Se puede afirmar que el nuevo contexto, el desarrollo se traslada desde el centro hacia el sector territorial y local, por los siguientes aspectos:

\footnotetext{
1 Alburquerque, Francisco. "Desarrollo Económico Local y distribución del Progreso Técnico" (Una respuesta a las exigencias del ajuste estructural) ILPES. Santiago de Chile. Diciembre de 1996. Pág. V. 2 Vázquez Barquero, Antonio. "Política Económica Local”, Ediciones Pirámides, S.A. - Madrid. 1993 Pág. 219.
} 
1. Las estrategias de desarrollo local tienen como objetivo el desarrollo y la reestructuración del sistema productivo, el aumento de la capacidad de creación de empresa y de generación de empleo y la mejora del nivel de vida de la población.

2. La vertiente económica del desarrollo local consiste en crear, dentro de un territorio dado, la capacidad necesaria para hacer frente a los retos y oportunidades que puedan presentarse en una situación de rápido cambio económico, tecnológico y social.

3. Los agentes de las políticas de desarrollo local son las autoridades públicas, los empresarios y actores socioeconómicos locales, y no sólo la administración central del estado y las grandes empresas, como sucedía en los modelos tradicionales.

4. Se tiene siempre en cuenta que las economías locales están integradas en el sistema económico nacional e internacional y que, por consiguiente, sus problemas son siempre problemas nacionales o internacionales, debido a que los sistemas productivos locales $\mathrm{y} / \mathrm{o}$ regionales son componentes de los sistemas nacionales y supranacionales.

5. Recogen, además, la importancia de "pensar global y actuar local".

6. Reconocen que pese al carácter esencialmente endógeno del desarrollo local los recursos externos juegan un papel importante en la dinamización del área.

7. Apoyan la integración de las instituciones, empresas y de la economía local en redes de carácter nacional e internacional.

8. Finalmente, y como elemento diferencial más importante, se reconoce que la coordinación y/o descoordinación de las acciones de todos los actores (internacionales, nacionales o locales) se producen en el territorio y que, por tanto, la visión estratégica desde lo local es relevante para el desarrollo económico y social nacional y supranacional.

De otra parte, Sergio Boisier (2004) señala que los núcleos de desarrollo Endógeno son "iniciativas productivas que emergen del interior de un territorio, sector económico o empresa, para aprovechar las capacidades, potencialidades y habilidades propias, con el fin de desarrollar proyectos económicos, sociales, ambientales, territoriales y tecnológicos, que permitan edificar una economía más humana, para una nueva vida económica del país".

Por eso, poder realizar un proceso de aprehensión de la realidad de las localidades de la provincia de Pamplona y particularmente de esta ciudad, es fundamental para poder empezar a estructurar las condiciones particulares de nuestro modelo de desarrollo endógeno. 


\section{PROCESOS HISTÓRICOS DE PAMPLONA}

\section{Particularidades de Pamplona}

En el presente escrito no se pretende realizar un estudio sucinto de la historia de Pamplona que de por si es muy extensa, sino identificar de manera precisa los aspectos más generales y reconocer los procesos que han persistido como hilos conductores y que han signado a la ciudad de manera particular diferenciándola de manera clara y que constituyen el punto de partida para, profundizándolos y sacándolos a flote intuir cual es la ruta de sus posibilidades de desarrollo.

Por supuesto la inspección del pasado arranca desde los primeros momentos de la época colonial, se van reafirmando y se revalidad en la fase republicana y se manifiestan de manera evidente en nuestros días.

Para los pamploneses es claro que el nombre de la ciudad que fundaran en 1459 Pedro de Ursúa y Ortún Velasco de Velásquez en homenaje a la capital de Navarra no podía ser otro que Nueva Pamplona del Valle del Espíritu Santo.

Desde allí partieron las expediciones que fundaron, entre otras, a Mérida, San Cristóbal y La Grita (en Venezuela); y Ocaña, Salazar, Chinácota, San Faustino, Bucaramanga y San José de Cúcuta (en Colombia) y que le dieron el titulo de ciudad fundadora de ciudades.

$\mathrm{Al}$ igual que la mayoría del territorio santandereano al momento de la fundación, estaba habitado por los Chitareros, familia Chibcha, a los cuales sometieron en alrededor de 100 grupos o capitanejos que fueron repartidos en 53 encomiendas por todo el territorio.

\section{En la Época Colonial}

A partir de la investigación histórica sobre Pamplona, podemos identificar uno de los elementos más importantes, que se convierte en la punta de ese hilo conductor que va enrollando la madeja de la historia, que luego se reencarna bajo otros cuerpos, formas y expresiones que se ha mantenido por más de quinientos años y tiene que ver con las funciones que le asignaron las autoridades colonizadoras y que cumplieron algunos centros urbanos fundados por los españoles en el siglo XIV y que le dieron a estos unas características particulares.

Para lograr la identificación de las características que han persistido en el tiempo del municipio de Pamplona debemos tener presente que los colonizadores españoles construyeron ciudades de diferentes tipos según su función principal: 1) aquella que formaron parte de la estrategia de defensa como Cartago; 2) las que sirvieron como 
centro de la producción minera como Mariquita en el Tolima, 3) las que cumplían funciones de distribución por su posición geográfica y cercanías con la vía fundamental de comunicación en el interior del virreinato, el Rio Magdalena, como Honda y 4) los centros administrativos por excelencia donde se asentó el poder político como Bogotá, Tunja y Pamplona, ejes de organización de todo el espacio circundante.

Para el caso de Bogotá y Tunja, ellas se fundaron en espacios con abundante mano de obra indígena y gran desarrollo agrícola, pues en esos territorios se concentró la mayor proporción de la población de la nación Chibcha. En ellas se organizaron y usufructuaron los excedentes que producía la región circundante.

Era claro para los españoles que la ciudad debía cumplir una función especial pues a partir de ella se organizaba la región y no al contrario, como sucedió en el proceso de formación de las ciudades europeas. Pamplona al igual que Tunja, cumplieron esas condiciones porque fueron asiento de los encomenderos que usufructuaron las riquezas y la mano de obra indígena de sus territorios circunvecinos.

Para el caso de Pamplona, la constitución de una red urbana temprana en el centro de Santander debe verse como producto de la aparición de un modelo sustitutivo de la sujeción de los pueblos de indios a las necesidades de mano de obra de encomenderos y propietarios que residían en la ciudad de españoles y desde allí ejercían un poder sobre el entorno rural.

Este aspecto lo confirma Germán Colmenares cuando establece que la evolución demográfica de varias regiones, tales como las de Santa Fe, Tunja, Vélez, Pamplona, Cartago, Pasto y Popayán, presentan situaciones similares.

En estas zonas existían pueblos indígenas sedentarios que habían alcanzado niveles altos de cohesión y organización social, que les permitió a los colonizadores, dominarlos y sujetarlos al régimen de la encomienda, e imponerles los sistemas de producción a los cuales no estaban acostumbrados, como las jornadas de trabajo de sol a sol.

Los diferentes estudios que han abordado las particularidades de las formas de producción indígena sostienen que ellos solo trabajaban en el año aproximadamente 40 días, durante los cuales producían los productos que requerían para su subsistencia, no producían mas porque dentro de su percepción de las necesidades no existía como objetivo determinante el buscar procesos de acumulación de riqueza.

Al sujetarlos a unas nuevas condiciones de trabajo absolutamente desconocidas para ellos (la jornada de trabajo diaria) les cambiaron radicalmente sus condiciones de vida y la historia así lo reseña cuando no informa para los territorios adscritos a la ciudad de 
Pamplona; que de 40.000 indios que había a la llegada de los españoles en 1549, se ha calculado que tan solo quedaban unos 6.000 un siglo después. El duro trabajo, las enfermedades y el mestizaje determinaron su rápida extinción.

Pero también encontraron otras naciones que mantuvieron su oposición y resistencia a la dominación española y que incluso prefirieron el suicidio colectivo antes que soportar la dominación, muchas de las cuales aun hoy persisten como los Bari y la Wua.

En la historia de la colonia la ciudad cumplió con una serie de funciones, y lo pudo hacer, porque las condiciones materiales de la sociedad y del espacio así se lo permitieron, ellas fueron:

1. "Pamplona, debió cumplir una función política durante el siglo XVI en los repartimientos del botín de la conquista. Primero las encomiendas y luego las mercedes de tierras, le confirieron una primacía política como albergue de encomenderos y como asiento de un cabildo que otorgaba mercedes.

2. A diferencia de Tunja, que conservó este primado político como cabeza de un enorme corregimiento, Pamplona y Vélez se vieron privadas de una parte de su jurisdicción con la aparición de otras villas en el curso del siglo XVII, San Gil, Girón y Socorro. Pero mientras Vélez se "perdió en la historia" al suprimirse la función identificadora que los españoles le asignaron, Pamplona la conservo.

3. La presencia de una población indígena abundante servía para subrayar cierto carácter señorial de los centros urbanos. Las explotaciones auríferas de Pamplona y de Vélez redujeron muy pronto una población indígena relativamente escasa y permitieron la aparición de villas rivales que sustentaban su desarrollo en las actividades de labradores y artesanos. Contra el carácter patrimonial de viejas ciudades de españoles como Tunja, Vélez y Pamplona, la villa de labradores presenta un carácter aldeano muy similar al de los pueblos mestizados que se convierten en parroquias a finales del siglo XVIII.

4. La constitución de una red urbana temprana en el centro de Santander debe verse como la aparición de un modelo sustitutivo de la sujeción de los pueblos de indios a las necesidades de mano de obra de encomenderos y propietarios que residían en la ciudad de españoles y desde allí ejercían un poder sobre el entorno rural.

5. Por su localización estratégica, en el cruce de los caminos más importantes del noreste de lo que hoy es Colombia y especialmente por estar sobre la ruta del lago de Maracaibo hacia Santa Fe, fue centro comercial. Esta ventaja comparativa sumada al creciente desarrollo agrícola fortalecido por la economía, institución - socio - económica de gran desarrollo de la provincia en la época colonial y que permitió el asentamiento definitivo de una Casta 
Española, tuvo que ver mucho en el auge socio - económico y político de Pamplona y su provincia durante los coloniales siglos XVII Y XVIII.

Es claro que el estatus conferido a Pamplona dentro del marco de la política colonial no fue el de una villa coordinadora de labradores que dependía fundamentalmente de las actividades agropecuarias, sino el de servir como centro político, religioso y comercial de un extenso territorio que sobrepasaba los límites de la hoy conocida como Provincia de Pamplona, del Departamento Norte de Santander y que incluso llegaba a vastos territorios de Santander, Boyacá y hasta Venezuela.

La ciudad fue casi desde su fundación, asiento de instituciones políticas coloniales, de instituciones religiosas. La presencia de varias congregaciones religiosas masculinas y femeninas y las múltiples iglesias dan cuenta de su importancia en esta materia.

\section{En el siglo XIX}

La ciudad fue parte importante del proceso de lucha por la independencia y fue destino de varias migraciones hacia su territorio; primero con el movimiento comunero llegan algunas familias procedentes de Socorro, luego con la guerra de independencia afluyen venezolanos de los valles bajos del Zulia y Pamplonita, posteriormente entra a formar parte de la ruta del cacao y hacia 1840 comienza un proceso de migración hacia las tierras de clima medio producto de la expansión del cultivo del café; estos sucesos forman parte de los hilos conductores que cumplía desde la colonia y que se reafirman con la expansión cafetera hacia finales del siglo XIX, igualmente se va ver afectada por el surgimiento de nuevos municipios como El Carmen, San Calixto, Cáchira, Teorama, Convención, Gramalote, Durania, Herrán, Sardinata, Ragonvalia, Lourdes, resultado de un proceso de penetración y adaptación de tierras que aún dura en nuestros días.

La rápida creación de tantos municipios en la naciente zona cafetera no solamente minó la base tributaria sino que el nuevo esquema político administrativo restringió el poder político económico y social de Pamplona.

Adicionalmente los cambios de mitad de siglo XIX y el desarrollo del café les permitió a los comerciantes de Pamplona invertir sus capitales en la conformación de haciendas cafeteras; pero hacia comienzo del siglo XX, cuando esta actividad empezó a trasladarse, primero hacia Cundinamarca, Tolima y Antioquia y después hacia la región del viejo Caldas donde los factores geográfico-ambiental y el tipo de sociedad allí existente hicieron posible que la vida económica del país se trasladará de oriente a occidente consolidándose allí una economía cafetera que relegó la zona del Norte de Santander a un plano secundario.

Efectivamente la ciudad de Pamplona y su área de influencia regional(Provincia) fueron escenario de un proceso histórico que involucró con intensidad variables geográficas, 
socio económicas, políticas y culturales pero cuya principal característica es la de haber sido epicentro espacial de las coyunturas que caracterizaron los desarrollos coloniales y republicanos y que culminaron en la estructuración y definición de la actual ciudad como centro de prestación de servicios estatales, educativos y de comercio en primera instancia para una provincia cuya economía se basa en la explotación agropecuaria de tipo tradicional y en segunda instancia, el haber traspasado los límites de las sociedades rurales agropecuarias que la rodean y convertirse en una fuente de atracción de población de disimiles territorios nacionales y extranjeros.

\section{Procesos económicos en el siglo XX}

Cuando se aborda el estudio de la Historia Económica Colombiana y particularmente el origen de la industria en nuestro país, es necesario identificar las limitantes para su expansión.

Sin lugar a dudas el elemento que impidió una rápida expansión y crecimiento de la industria tenía que ver con la estrechez del mercado interno y con una de sus causas: la falta de vías de comunicación que hicieran posible el tránsito de los bienes por las regiones de Colombia. Este aspecto produjo que la naciente industria tuviera un marco local y cuando mucho regional, pues los costos de transporte eran excesivamente altos, cuando existían vías o que su traslado vía transporte animal fuese imposible.

Pamplona, ciudad coordinadora de villas de aldeanos que requerían bienes y servicios tenía el campo fértil para que aparecieran, como en el resto de ciudades del país, algunas industrias que tuvieran un nicho de mercado y que surtieran esas demandas insatisfechas. Por eso surgen entidades de carácter financiero, artesanal, comercial, industrial; que le van a reconfirmar por la vía de la práctica la función adquirida desde la colonia.

\section{Los bancos}

En la ciudad y consecuente con el tipo de función que cumplía desde la época colonial, se produjeron importantes acontecimientos como la fundación del Banco de Pamplona (el tercero que se fundó en el Estado Soberano de Santander) y llegó a tener sucursal en Cúcuta, debido a su comercio fronterizo.

Se constituyó por Escritura Pública N 536 del 10 de octubre de 1882, con un total de 67 socios, como sociedad anónima, de capital limitado, con una duración de 15 años prorrogables. Su capital inicial fueron 80.000 pesos, representados en 320 acciones de 250 pesos cada una. Empezó a operar el 1 de enero de 1883. Los socios fueron principalmente hacendados de la región y de las provincias de Soto y García Rovira, interesados en crear una institución financiera para el fomento de la agricultura. 
Sin embargo, al poco tiempo de su apertura el Banco de Pamplona comenzó a sufrir dificultades que lo llevaron a su cierre. Sin embargo, el Banco de Pamplona volvió a organizarse a comienzos de este siglo, después de 1910, cuando ya la ciudad era parte del Departamento de Norte de Santander. El Banco funcionó algunos años, pero con las reformas a los bancos comerciales producto de las recomendaciones de la misión Kemmerer en 1923 que crearon el Banco de la República, debió unirse a los bancos de Santander y de Cúcuta, para luego incorporarse al Banco de Bogotá en 1928, desapareciendo definitivamente.

\section{La industria}

En relación con la industria y los procesos artesanales, en la ciudad surgen una serie de empresas que tienen por objeto surtir la demanda domestica y la de los pueblos vecinos, ya que no existían posibilidades que empresas de otras partes del territorio lo hicieran. La industria de los alimentos, bebidas y otros productos aparecieron en la ciudad, al igual que en el resto del país, hacia la década del 30 del siglo XX.

Para el año de 1930 se funda en pamplona la Navarro Han. Llamada también Cervecería "La Favorita" que producía la cerveza negra "Favorita" que funcionó en forma artesanal hasta los años ochenta; luego, el Señor Luis Arturo Rojas funda en 1939 las Industrias Apolo, que producía la marca "Cerveza Negra” y bebidas gaseosas muy famosas por la época en la zona, la cerró en el año de 1964.

Estas dos empresas cubrían el mercado local y el de las poblaciones de la provincia como Chitagá, Cácota, Silos, Bochalema, Pamplonita, Labateca y Toledo entre otras y sus productos eran muy apetecidos por el mercado.

De la historia oral de la ciudad, vale la pena traer a cuento las narraciones de la llamada Esquina Industrial. "Quedaba donde hoy es la concentración Galán; Se le llamaba así, porque en esa esquina habían cuatro fábricas: la fábrica de cerveza negra y maltina con el nombre de parra: cerveza negra parra y, maltina parra. También fabricaban cola (gaseosa), cola champaña parra; en la mitad de la cuadra (subiendo por lo que es hoy la concentración galán) había un campo inmenso donde estaba la fábrica de chocolate "la proveedora". Una maquinaria completísima elaboraba la pastilla de chocolates como el que hoy conocemos; en la parte de abajo haciendo escuadra con la galán, estaba "el zaque "; destiladora de aguardiente: aguardiente de pamplona, tinas enorme donde se enfuertaba el guarapo y lo ponían en maceración en sótanos, de esas tinas salía el guarapo a los alambiques y por vapor se producía el aguardiente. Al frente del saque quedaba la primera y tal vez única fábrica de adobes mecanizada, (trajeron cuatro maquinas, manejadas por los presos. Uno preparaba la tierra; otro, en zurrones, la llevaba a la maquina y los otros dos, cada uno, tomaban las palancas del aparato y producían cada minuto un adobe). 
La Industria Lara quedaba donde hoy es la molinera de Herrán, que hizo las primeras telas de zaraza y liencillos y una especie de tela gruesa (bayetilla); luego, hacia arriba habían unos molinos (no los de Herrán) y al frente, donde hoy está la normal, estaba una finca,(Lara), donde funcionaba una fábrica de fósforos.

Había también una "pelton inmensa, en donde trabajaban el oro, que traían de los minas, de carava o de paramo rico. En esos patios molían la arena de oro".

Posteriormente el señor Pedro Felipe Lara funda para el año 1924 una industria en el casco urbano de Pamplona llamada La Molinera De Herrán, esto se debió a que la ciudad contaba con fluido eléctrico y otros factores, así mismo la industria se expandió hacia los municipios de Málaga y Mutiscua, siendo este último el más rentable por contar con un rio que era indispensable para el funcionamiento del molino, tuvo agencias en Bogotá, Bucaramanga. En este sentido la materia prima era traída de Boyacá, Silos y Cacota, y Estados Unidos; la industria tuvo una etapa económica floreciente contribuyendo al desarrollo de los habitantes de la región, desafortunadamente fue decayendo paulatinamente, debido a los cambio que se produjeron cuando rápidamente la harina de trigo importada de USA, fue sustituyendo a la nacional y el cultivo del producto fue desapareciendo, cerro en1989.

Fue una pérdida muy grande para la ciudad pues ocupaba 20 empleados, contaban con 18 maquinas, 6 de banco, 6 rechinadora para la limpieza del trigo, y 6 molineras que eran las que terminaban con la elaboración del producto, existía un calentador grande, en donde lo llenaban de agua y lo prendían con carbón cuando no había luz, para seguir con la producción.

Igualmente y por las condiciones de la economía nacional la cervecera Bavaria instalo una planta de producción en la ciudad donde producían la malta. Utilizaban 4 maquinas de limpieza, 4 envasadoras, 4 embotelladoras y 4 selladoras, ocupaba 50 empleados; su cierre, producto de la racionalidad económica y de los cambios en las vías de comunicación, no se hizo esperar, pues no era rentable.

\section{El comercio}

El comercio se desarrolló desde la época colonial y los historiadores así lo reseñan; en la obra "Los Caminos Reales en Colombia" el historiador Jorge Orlando Melo plantea que "En el siglo XVIII florecieron en el comercio las ciudades de Tunja, Socorro, San Gil y Pamplona" y en el siglo XX y XXI ha tenido tres fases claramente diferenciadas.

En el siglo XX con la construcción de la Plaza de Mercado el comercio se fortaleció, pues alrededor de ella se concentraron los establecimientos comerciales más importantes y que tenían como objeto no solo surtir la demanda de la localidad sino también la de las poblaciones de la provincia. Hacia ese sitio arribaban los vehículos 
provenientes de Toledo, Labateca, Chitagá, Cácota, Silos, Mutiscua, Bochalema y demás municipios del área de influencia de la ciudad.

La segunda fase se origina por cuenta del diferencial cambiario Bolívar-Peso, ya que durante una buena parte de las décadas del cincuenta y el sesenta se presento un proceso de devaluación del peso que se profundizo a partir de la devaluación "gota a Gota” del gobierno de Lleras Restrepo y que alcanzo 17 pesos por Bolívar.

Este hecho económico produjo dos situaciones: flujo estudiantil de venezolanos que demandaban cupos en los colegios privados o semiprivados del municipio y flujo de compradores venezolanos a quienes les favorecía el diferencial cambiario y podían adquirir las mercancías colombianas tan apetecidas en el país vecino.

Es en la década del sesenta es cuando se fortalece el comercio en la calle real fundamentalmente con establecimientos comerciales de inmigrantes árabes dedicados a la venta de vestuario y calzado, con productos de las fabricas de Medellín, Pereira y Bogotá.

La tercera fase se inicia con el auge de la Universidad de Pamplona que genera un crecimiento acelerado de esta actividad pues no solo se multiplican los negocios, sino que se diversifican notablemente.

\section{PROCESOS ECONÓMICOS ESPONTÁNEOS DINÁMICOS}

\section{El turismo}

Otro de los hilos conductores que han persistido en el tiempo hace referencia a Pamplona como ciudad turística. Desde la época colonial la ciudad fue centro de atención de los pueblos y parroquias vecinos y cruce de camino en la ruta Bogotá-Lago de Maracaibo y sus festejos religiosos se empezaron a conocer ampliamente. El turismo ha llegado a la ciudad gracias a tres elementos determinantes: la religión, el ser ciudad colonial y el ser ciudad estudiantil.

\section{Turismo religioso}

Una de las funciones que cumplió la ciudad desde la colonia fue la de ser centro religioso. No hace más de 30 años se la identificaba como la ciudad de los campanarios, curas y monjas, las comunidades religiosas, las imágenes religiosas conocidas por ser milagrosas y cuya fama se expandió en el tiempo hacia otros territorios, las celebraciones de la semana santa y los festejos del señor del Humilladero entre otros, atrajeron a los creyentes y se convirtieron en una importante fuente de ingresos para los comerciantes de la ciudad y la población en general. 
En un portal de la red www.turismocolombia.com se encuentra la siguiente información: "Las celebraciones de Semana Santa de Pamplona, el segundo destino más antiguo del Norte de Santander y el pueblo de una indescriptible belleza arquitectónica, son, al lado de las de Popayán y Mompox, las más importantes y reconocidas por los católicos en Colombia. Heredada de la tradición española y enriquecida por los elementos propios, la Semana Santa en Pamplona es un patrimonio de esta tierra de casas pintorescas, de nieblas en los jardines, de rezos y del misticismo local".

Pero la Semana Santa no explica el fenómeno turístico; ello tiene que ver con las historias y leyendas de las imágenes religiosas emblemáticas de la ciudad mitrada: El Cristo del Humilladero y El Niño Huerfanito, los túneles que comunican edificios religiosos y en fin un sinnúmero de historias. Veamos algunas:

\section{Leyenda del Cristo del Humilladero}

El Señor del Humilladero, que según la tradición oral trasmitida de generación en generación, fue tallada en madera por dos extraños que en la época de la Colonia le pidieron a un párroco de Pamplona que los dejara hacer la talla.

La única condición que pusieron fue un cuarto cerrado donde trabajar y que no los molestaran, ni siquiera por la comida. Al cabo de veinte días de estar encerrados, las personas del servicio dejaron de oír los cinceles con que tallaban la figura y entraron al cuarto para ver a los dos talladores, pero estos habían desaparecido y la figura del Humilladero estaba lista, tal y como permanece ahora, cuatrocientos años después. La mitología religiosa dice que fueron ángeles del señor los que construyeron la milagrosa estatua, que hoy se exhibe en la iglesia del Humilladero y que es visitada por cientos de fieles todo el año.

\section{E1 Niño Huerfanito}

Cuenta la historia que en ese entonces un terremoto sacudió a Pamplona y dejó en pie muy pocas edificaciones. Una hermana clarisa que salió ilesa del sismo se acordó de repente que la imagen de la Santísima Virgen con el niño en sus brazos podía seguir en pie. Pensando en esto corrió hacia el interior del convento derruido gritando que el niño se había quedado huerfanito. En ese momento un nuevo remezón acabó de tumbar las vigas del techo que cayeron sobre la religiosa. Días después, cuando removieron los escombros, el cuerpo sin vida de la hermana apareció bajo las vigas pero la imagen del niño estaba sobre uno de los maderos, intacta y con una mano levantada, como si estuviera dando la bendición a la benefactora que le salvó del desastre.

Estos dos ejemplos de los muchos que existen explican el flujo turístico de carácter permanente que llega a la ciudad. 


\section{Turismo a la Ciudad Colonial}

Es sin duda uno de los elementos atrayentes para los turistas nacionales y extranjeros. A pesar de la enorme depredación de la arquitectura colonial y republicana, todavía quedan reliquias que le permitirán, dotándose de una estrategia, recuperar y mantener ese atractivo. Aquí encontramos algunos sitios de interés que la posicionan como un valor importante: la Ermita de la Nieves, construida por los conquistadores en noviembre de 1549. Fue restaurada en 1931 y nuevamente en fecha reciente. Plazuela de la Ermita, de las tres plazuelas originales es la única que existe. Iglesia del Monasterio de Santa Clara. Data del siglo XVII. A partir del terremoto de 1875 recibió los oficios de la catedral. Sobre ella entre 1917 y 1920 fue construida la Catedral de Pamplona y entre 1987 y1988 fue restaurada a su estado original. Casa donde se fraguó el golpe del 4 de julio de 1810. Perteneció durante varias décadas a la Familia Villamizar y Pineda, de esta casa fue Propietaria Doña Águeda Gallardo Guerrero, esposa que fue de Don Juan Antonio Villamizar Peña. Data del siglo XVI. Casa de las Cajas Reales y tesorería de ésta; también fue Gobernación de la Provincia y en ella se redactó la Constitución del Estado soberano de Santander en 1857. Data de finales del Siglo XVIII y fue restaurada entre 1980 y 1983. Actualmente funciona en ella el SENA. Casa de los hermanos Zapata, Dámaso y Felipe, donde funcionó la primera imprenta en 1849. Mansión señorial de la familia Rangel del Cuellar. Esta cada ha sido el palacio de los Obispos de Pamplona desde mediados del Siglo XIX. Casa Parroquial de las Nieves, construida por orden del Vicario Dr. Domingo Tomás de Burgos, Colegio de la Compañía de Jesús. Es la cada de mercado desde 1920. Iglesia de Santo Domingo. Data de 1563; en el año de 1988 se le hicieron obras de mantenimiento y algunas modificaciones. Ermita del Humilladero. Data 1686, fue restaurada en 1931 y nuevamente en 1988. Casa Consistorial, Funcionó en ella el Cabildo, los despachos de los alcaldes ordinarios y la cárcel. Hoy en día está allí la Alcaldía de la ciudad. Casa natal del General Leonardo Canal, prescindente de Colombia en 1863. Cll 6 \#3-91 y Cra 4 \#5-94. Casa Natal de Sor Gertrudis Teresa de Santa Inés. Cll 6 \#4-09 / 15.

\section{Turismo ligado a la Ciudad Estudiantil}

Desde la colonia en la ciudad se asentaron congregaciones religiosas que cumpliendo con las normas de la Corona española se encargaron de la enseñanza de indios y de los habitantes de la villa. Uno de los establecimientos educativos lo reseña el Jesuita Fortunato Herrera en un artículo titulado "Los Colegios de la Compañía de Jesús en Colombia”, quien consigna que en 1625 se fundó el Colegio de Pamplona y el presbítero informa que en la época de la Independencia Monseñor Lasso de la Vega frecuentó la ciudad en donde fundó el Colegio Provincial de San José y el Colegio de Ordenandos que daría origen al Seminario Conciliar.

Ya en el siglo XX la ciudad se destacó por la existencia de instituciones educativas que fueron atrayentes para quienes deseaban cursar estudios secundarios que ofrecían los servicios de alojamiento, alimentación y educación. En las décadas del 40, 50 y 60, los 
estudiantes de ciudades y poblaciones cercanas eran matriculados en los establecimientos de Pamplona.

Cuando el diferencial cambiario del Bolívar con respecto a la moneda nacional era ampliamente favorable para el primero, y, la creencia generalizada en Venezuela de que la calidad de la educación era superior en Colombia, se produjo una corriente creciente de estudiantes provenientes de diversas regiones del país vecino, que abarrotaron los colegios de la ciudad. Por ese entonces era frecuente ver los internados del Colegio Provincial (uno de los más antiguos del país), del Carmelitano, del Gimnasio del Rosario, El Rosario y las Terciarias, entre otros, repletos de internos venezolanos en una relación de por cada 100 estudiantes 70 eran venezolanos y los 30 restantes colombianos.

Evidentemente esta situación generó una corriente de importantes ingresos que hicieron posible el crecimiento del sector comercial y de confecciones, como también del turismo hacia la población que vino a reforzar el carácter de ciudad prestadora de servicios y que produjo en ese periodo una nueva generación de comerciantes ansiosos de aprovechar las ventajas del intercambio y del mayor valor de la moneda venezolana.

Años más tarde, en la década del 80, el Bolívar se derrumbó y la ciudad entró en una recesión, pues la demanda se redujo a la local y a la de los municipios de la provincia.

El turismo ligado a las características de ciudad estudiantil desapareció y la tendencia generalizada fue la de sustituir la educación privada por la pública, surgiendo así la segunda generación de establecimientos educativos que tenían por objeto darles a las clases más desfavorecidas de la ciudad la oportunidad de educarse.

\section{La Universidad de Pamplona}

Un nuevo proceso se inicio a finales del siglo XX, con el crecimiento acelerado de la Universidad de Pamplona que en un lapso de 7 años tuvo un crecimiento del seiscientos por ciento, pasando de un poco mas de 2.000 estudiantes a tener más de 13.000.

Miles de jóvenes provenientes de las más distantes regiones de la costa atlántica, los llanos orientales, Nariño, Amazonas e incluso venezolanos empezaron a estudiar en la universidad de Pamplona y a generar una demanda para la cual la ciudad no estaba preparada.

En ese periodo no solo creció el número de estudiantes, sino también la construcción de infraestructura, el número de profesores y por consiguiente las necesidades de esa nueva población que vivía en la ciudad por lo menos 10 meses del año. 


\section{Emprendedores}

Las posibilidades de desarrollo endógeno van de la mano con el surgimiento, conservación y desarrollo de las empresas y para el caso de Pamplona el crecimiento de las mismas ha sido significativo; de acuerdo con la Cámara de Comercio, las empresas pasaron de mil seiscientas en el año 2003 a cerca de 3000 en el 2008.

Los procesos de emprendimiento significativos que se han presentado han estado ligados a los dos eventos económicos más importantes de la ciudad: el turismo y la Universidad de Pamplona. Hemos escogido dos casos que son insignia de la ciudad para mostrar la persistencia y el impacto: Pierino Romany y el ex rector de la universidad de Pamplona del periodo 1997-2008.

Uno de los restaurantes más emblemáticos de la ciudad es la famosa pizzería Piero's de propiedad de Pierino Romany, uno de los emprendedores más destacados de Pamplona, dado que su establecimiento se ha mantenido por 25 años tras una constancia en la calidad de su servicio.

Pierino Romany es un inmigrante italiano que pasada la segunda guerra mundial decidió emigrar a Venezuela, en 1954, en pleno gobierno del dictador Pérez Jiménez. Con 20 años de edad llegó a Caracas, sin saber hablar español, trabajo como albañil en construcción y posteriormente se fue a trabajar en una petrolera. Poco tiempo después llego a Pamplona y conoció a un alemán que tenía un restaurante ubicado al lado de la plaza que se llamaba el restaurante Granada. Un amigo italiano de Cúcuta que iba a Pamplona los fines de semana, le fue enseñando a preparar platos a la carta y a hacer pasta italiana; por lo que se fue especializando y adquiriendo clientela. En 1959 vino una época difícil, pues el bolívar a cayó a 80 centavos, todo el mundo quebró al igual que él; por lo que siguió manteniéndose con la venta de tallarines fabricados con una maquinita italiana que había adquirido.

En 1960 se entera que en Pamplona estaban arrendando el hotel Anzoátegui y arrendó el primer piso pero no persistió, luego arrendó un local cerca al parque en donde vendía comida con su esposa y fabricaba tallarines. Viajo a Italia y regreso seis meses después encontrándose que el restaurante Granada estaba quebrado lo compra en el 1965 y le coloca el nombre de restaurante Italia. En 1970 ganó la lotería, \$32000, y empieza a construir un hotel en el actual Piero’́s. En 1983 volvió a caer el bolívar, con la crisis subsiguiente y decide montar la pizzería en los locales de los apartamentos, pues este era un trabajo más práctico y ya tenía clientela. Le puso piero’́s por su nombre, en 1996 monta una sucursal en Cúcuta, que actualmente está ubicada en el barrio Popular. En agosto de 2008 cumplió 25 años la pizzería gracias a la constancia y la calidad con la que se ha destacado desde siempre. 
El segundo ejemplo es el de un ex rector de la Universidad de Pamplona quien es natural de Pamplona y uno de sus personajes más controvertidos. Regreso a la ciudad en la década del noventa del siglo pasado y asumió la rectoría del alma mater.

Es evidente que se sentía identificado con el modelo educativo neoliberal que se venía impulsando desde 1990 en el país y que lo quería implementar. Por eso sin ningún proceso de planificación, llevado solo por su instinto, emprendió el más grande crecimiento de la universidad en toda su historia y cuya información se encuentra en un libro editado en su administración.

Es posible que no midiera el impacto que tendrían sus decisiones en la ciudad, como tampoco de la posibilidad de que su esquema fuera sustentable.

Vale la pena aclarar en este trabajo que se está reconociendo un hecho económico objetivo incontrastable, cual es las consecuencias que produjo en la ciudad.

\section{Impacto directo de los procesos espontáneos dinámicos en Pamplona}

La ciudad creció siguiendo a la universidad. Primero para satisfacer las necesidades básicas: alojamiento y alimentación y luego porque la población estudiantil tenía otra serie de necesidades.

De acuerdo con la información de la cámara de comercio de la ciudad para el periodo de 1998 a 2008, la creación de empresas tuvo un comportamiento dinámico y originado por el crecimiento de la matricula en la Universidad de Pamplona. En el siguiente cuadro podemos observarlo:

\section{Creación de empresas en Pamplona}

1998-2008

\begin{tabular}{|l|c|c|c|}
\hline Año & $\begin{array}{c}\text { Número de } \\
\text { Empresas creadas }\end{array}$ & \% Comercio & \% Servicios \\
\hline 1998 & 369 & 55 & 39.2 \\
\hline 1999 & 292 & 42 & 50.7 \\
\hline 2000 & 459 & 50.8 & 41.4 \\
\hline 2001 & 477 & 39.8 & 51.2 \\
\hline 2002 & 657 & 45.3 & 43.8 \\
\hline 2003 & 498 & 52.8 & 46.2 \\
\hline 2004 & 640 & 39.4 & 54.2 \\
\hline 2005 & 690 & 51.3 & 44.9 \\
\hline 2006 & 670 & 43.3 & 50.6 \\
\hline
\end{tabular}




\begin{tabular}{|l|l|l|l|}
\hline 2007 & 790 & 46.8 & 46.2 \\
\hline 2008 & 739 & 48.2 & 46.1 \\
\hline
\end{tabular}

Fuente: Cálculos Propios con base en la información de la Cámara de Comercio de Pamplona.

Igualmente se puede indicar, de acuerdo con la información mencionada, que existía una relación en la misma dirección entre aumento de estudiantes de la universidad y crecimiento de las empresas dedicadas al comercio y a los servicios. Si sumamos para el periodo el porcentaje de empresas creadas en actividades de comercios y servicios, encontramos que durante el periodo ellas sumaron más del $90 \%$, quedando menos del $10 \%$ de empresas creadas para actividades diferentes.

Otro hecho indicativo del proceso de crecimiento de la actividad económica de Pamplona ha sido la atracción que ha ejercido sobre empresarios exógenos que se han asentado en el municipio a raíz del crecimiento de la universidad. Las actividades predilectas de los foráneos están dentro de los servicios, pues han fundado restaurantes que expende comida costeña a la vez que ofrecen el servicio de alojamiento para los originarios de esa región; igual cosa ocurre con los procedentes de los llanos orientales.

\section{La Construcción}

Con la construcción del campus, la ciudad creció alrededor de ella pues los estudiantes demandaban alojamiento cerca de la universidad. Pero el déficit habitacional puso en evidencia que era necesario realizar nuevas construcciones. En la siguientes graficas podemos observar la dinámica de esta actividad.

\section{Evolución de las licencias de construcción en Pamplona 2002-2008}

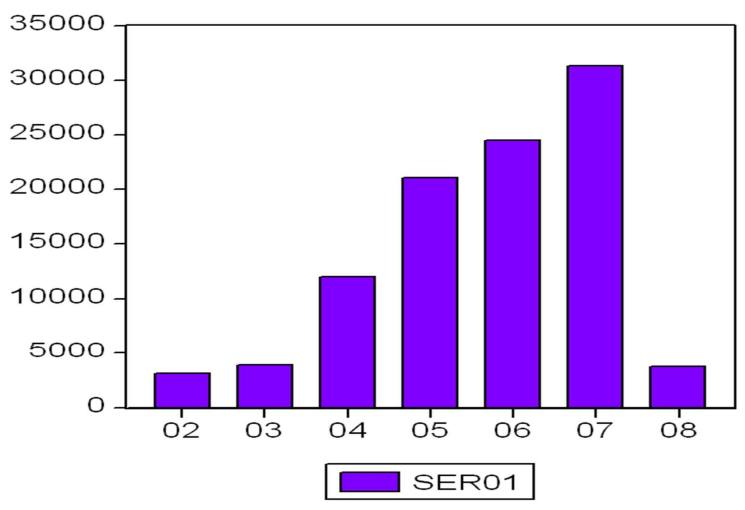

Fuente: Cálculos propios con base en las Licencias de Construcción Secretaria de Planeación, Alcaldía de Pamplona. 


\section{Evolución de las licencias de construcción en Pamplona 2002-2008}

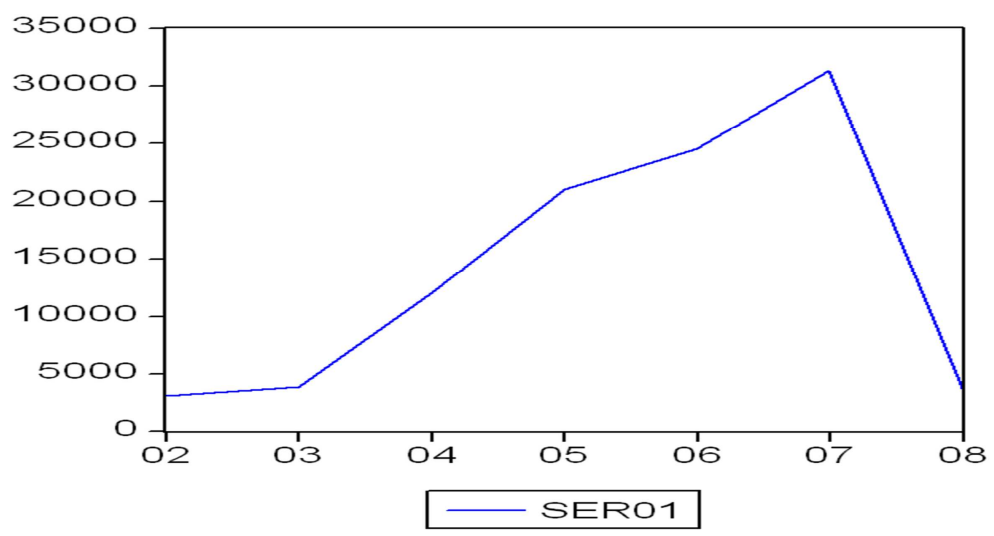

Fuente: Cálculos propios con base en las Licencias de Construcción Secretaria de Planeación, Alcaldía de Pamplona.

\begin{tabular}{|l|l|l|}
\hline \multicolumn{3}{|c|}{ Cuadro construcción en Pamplona } \\
2002-2008 \\
\hline Año & Metros construidos & $\%$ de crecimiento \\
\hline 2002 & 3.092 & \\
\hline 2003 & 3.913 & 26.5 \\
\hline 2004 & 12.005 & 106.8 \\
\hline 2005 & 21.052 & 75.3 \\
\hline 2006 & 24.517 & 16.5 \\
\hline 2007 & 31.320 & 27.8 \\
\hline 2008 & 3.716 & -88 \\
\hline
\end{tabular}

Fuente: Cálculos propios con base en las Licencias de Construcción Secretaria de Planeación, Alcaldía de Pamplona.

Del cuadro anterior podemos observar el comportamiento de la construcción originado por el crecimiento del número de estudiantes y profesores de la universidad de Pamplona que en el periodo observado aumento el número de metros construidos 99.615.

\section{Transporte}

El crecimiento del servicio de transporte también ha sido resultado del impacto que ha producido la población estudiantil en la demanda de servicios de transporte tanto 
urbano como intermunicipal y nacional. De los aspectos que cabe destacar en primer lugar la creación del servicio de transporte colectivo en busetas que cuenta con 27 busetas y varias rutas, la mayoría de las cuales se dirigen a la universidad; el establecimiento de rutas nacionales hacia la costa atlántica, el Valle del Cauca y Antioquia y los Llanos Orientales y el crecimiento del servicio de taxis urbanos e intermunicipales. El servicio de transporte público y encomiendas en la ciudad de Pamplona es prestado por tres cooperativas (Coopmotilón, Motilones y Cotranal) y está conformado por un parque automotor de 397 vehículos de los cuales 160 son taxis urbanos y 209 intermunicipales e interdepartamentales.

\section{Sector financiero}

En la ciudad desde hace muchos años han tenido sucursales los bancos Bogotá, Popular y Banco Agrario (antes Caja Agraria), pero con el crecimiento de la actividad económica han abierto sus puertas el BBVA, BANCOLOMBIA, DAVIVIENDAD y otras entidades financieras como Banca Mía, banco FMMB, Comultrasan, Comeva y Comultrup y un número significativo de cooperativas. Este aspecto muestra como ha impactado la demanda estudiantil a las necesidades de servicios financieros de la ciudad.

\section{Comercio}

El crecimiento del comercio ha sido dinámico, la ciudad cuenta con más de 50 almacenes que ofrecen confecciones, más de 10 discotecas, 8 bares y cerca de un centenar de establecimientos donde se expende licor.

De dos salas de internet que existían en el año 2001 ha pasado a 103, con el consiguiente crecimiento en la utilización de computadores; los negocios dedicados al expendio de insumos electrónicos tienen suficiente surtido para atender las demandas de los estudiantes y las papelearías han proliferado por toda la ciudad. Hoy la ciudad cuenta con varios centros comerciales que concentran importantes negocios.

Igualmente el crecimiento en los establecimientos dedicados al expendio de materia prima para la construcción por estar ligados a la construcción.

\section{Hotelería y similares}

La capacidad hotelera de la ciudad de pamplona esta alrededor de la acomodación de 951 personas distribuidos en los hoteles identificados y posadas cuyos precios oscilan desde los $\$ 30.000$ hasta los $\$ 150.000$ por habitación dependiendo de las características de la habitación y la capacidad de acomodación. La ubicación de estos hoteles está caracterizada por estar la gran mayoría dentro del centro histórico. 


\begin{tabular}{|l|c|}
\hline \multicolumn{2}{|c|}{ CAPACIDAD HOTELERA } \\
\hline HOTEL & N. PERS \\
\hline TERRAZA LOS PINOS & 32 \\
\hline H. EL SOLAR & 35 \\
\hline 1549 HOSTAL & 16 \\
\hline EL LLANO & 25 \\
\hline H. COOPMOTILON & 36 \\
\hline H. CARIONGO & 200 \\
\hline H.URSUA & 80 \\
\hline H. EL ALAMO & 69 \\
\hline H.IMPERIAL & 100 \\
\hline NORMANDIE & 26 \\
\hline TOTAL & $\mathbf{6 1 9}$ \\
\hline
\end{tabular}

Fuente: cuadro tomado del Informe de Pasantía "El Turismo Como Sector Económico Para El Desarrollo Y Crecimiento De Pamplona” Doris Portilla y Danny Villamizar, Departamento de Economía, Universidad de Pamplona.

\section{Industria y artesanías}

Aunque este sector no es importante en la ciudad, ha tenido una muy pequeña evolución pues los negocios de embutidos han aumentado, mientras que se sostienen aquellos dedicados al tostado y molido de café. Los tejidos que en el pasado tuvieron cierto dinamismo y que podrían convertirse en un elemento importante para el desarrollo endógeno, prácticamente desaparecieron y la elaboración de confecciones corrió con la misma suerte.

\section{BIBLIOGRAFÍA}

- BOISIER, Sergio, El Vuelo de la Cometa, EURE. Revista Latinoamericana de estudios urbanos regionales, $\mathrm{N}^{\circ}$ 69. AÑO 1997, Págs. 7 a 28.

- BOISIER, Sergio, Desarrollo (Local): ¿De Qué Estamos Hablando?, Cámara de Comercio de Manizales, 1999.

- BOISIER, Sergio, Crecimiento Y Desarrollo En El Territorio. ¿Casualidad?, ¿Resultado Esperado De La Complejidad Evolutiva?, ¿Construcción Social?

- colmenares, Germán.

- estrada gallego, Fernando, La Ciudad: Una Forma de Construir Mundos, Universidad Externado de Colombia, Bogotá 
- GUZMAN, Ángela, Poblamiento Y Urbanismo Colonial En Santander, Universidad Nacional, Bogotá, 1987,236 págs.

- PLANO, Ricardo, Historia de la Cerveza en Colombia.

- LONDOÑO, Ligia La Industria Bancaria en Colombia, Bogotá, 1958, págs. 44-45.

- ROMERO, Carmen Astrid, La Banca Privada en Santander, 1872-1925, Universidad Nacional de Colombia, 1987.

- VAZQUez BarQuero, Antonio, Política Económica Local, Ed. Prisma, 2002.

- Villamizar ANTOlinez, Eliseo, El Durazno: Un Proceso De Cambio En La Agricultura De La Provincia De Pamplona, Revista Face, año IV, No 7, Universidad de Pamplona, 2008. 